\title{
How Tropospheric Ozone Influences the Allelopathy of Woody Species: Some Experimental Approaches
}

\author{
Roshchina Victoria Vladimirovna \\ Laboratory of Microspectral Analysis of Cells and Cellular Systems, Institute of Cell Biophysics, Federal Research Center, Pushchino \\ Scientific Center for Biological Research of Russian Academy of Sciences, Pushchino, Russia
}

Email address:

roshchinavic@mail.ru

\section{To cite this article:}

Roshchina Victoria Vladimirovna How Tropospheric Ozone Influences the Allelopathy of Woody Species: Some Experimental Approaches. Journal of Plant Sciences. Special Issue: Use of Allelopathy in Agriculture: New Futures, Challenges and Future Prospects. Vol. 8, No. 4, 2020, pp. 71-79. doi: 10.11648/j.jps.20200804.11

Received: February 26, 2020; Accepted: July 22, 2020; Published: August 19, 2020

\begin{abstract}
Plants undergo a high concentration of tropospheric ozone formed mainly as a result of industrial and automobile pollution that may act on allelopathic relations in biocenosis. The problem was considered in first experiments modeling in test reactions with leaf leachates from 10 woody species as plant-donors, exposed to ozone, and able to influence on herbs (plant-acceptors) grown under their canopy. The effects were dependent on the duration and the intensity exposure to ozone. The color and the autofluorescence of the woody plant leaves with secretory cells contained allelochemicals changed under the ozone treatment. The effects of water extracts (models of rain leachates) from leaves of woody species exposed to ozone on the seed germination of herb Lavatera trimestris (Malvaceae), plant-acceptor of allelochemicals, differed from untreated samples. This showed a possible transformation of allelochemicals or/and the formation of new similar exometabolites after the ozone treatment. In the fluorescence spectra of whole leaves, the maxima, peculiar to phenols, were found at different experiments, while peaks related to terpenes disappeared in ozonated samples. Under acute or chronic ozone exposure the formation of biogenic amines (dopamine and histamine) known as allelochemicals was observed in leaf cells. These test-reactions on tropospheric ozone stress could be used in the analysis of allelopathic relations in urban conditions.
\end{abstract}

Keywords: Allelopathy, Allelochemicals, Autofluorescence, Germination, Lavatera trimestris, Tropospheric Ozone, Woody Species

\section{Introduction}

The realization of allelopathic plant characteristics in Nature depends on many environmental factors. Among them appears to be tropospheric ozone both of natural and urban origin [1, 2]. However, this problem was not considered yet by scientists working in the field of Allelopathy. Ozone or $\mathrm{O}_{3}$ is an allotropic modification of oxygen and is constantly present in the air [3,4]. This gas is forming in the atmosphere under the influence of ultraviolet radiation, and its concentration increases, especially in the morning hours, when the flow of UV radiation is maximal. Ozone also occurs in thunderstorms, which is most noticeable in the forest. Technological progress has contributed to the formation of ozone, as many modern instruments are emitters of ultraviolet rays, and therefore sources of ozone. Moreover, industrial and automobile pollution of the atmosphere leads to an increase of the oxidant concentration. Tropical and subtropical species may change their allelopathic characteristics more clearly than plants grown in a moderate climate [5]. Up to now, the soil nutrition and fire were known to influence on the allelopathic features of the genus [5], but no data connected with air-born conditions.

The herbal plants grown under or near trees/shrubs undergo the influence of leachates from trees that act on their development, especially on germination $[5,6]$. Besides active components of leachates, external air factors as tropospheric ozone may act on the allelopathic interactions. The first example was considered earlier with an allelochemical coumarin esculetin that transformed under the ozone exposure and changed its allelopathic effect on the 
germination of pollen Hippeastrum hybridum [7].

In a model system, tree/shrub-herb, changes that occurred in allelopathic plant characteristics could be highlighted by the use of test-reactions in laboratory conditions. The purpose of this paper is the analysis of changes that ozone induces in overground intact parts of plants and the leachate's content from trees and shrubs as well as leachate's effects on the herbs grown under or near the woody species.

\section{Materials and Methods}

\subsection{Plant Material}

Objects of the studies were tree plants grown in Sochi National Park (Dendrarium) [8] as donors of allelopathically active compounds and decorative herb plant Lavatera trimestris var. Rubin as acceptor of these allelochemicals. Woody plants tested include Eucalyptus cinerea F. Muell. ex Benth. (fam. Myrtaceae), Brachychiton diversifolius R. Br. (fam. Malvaceae), Ginkgo biloba L. (fam. Ginkgoaceae), Buddleja davidii Franch. (fam. Scrophulariaceae), Cassia floribunda Cav. (fam. Caesalpinaceae), Casuarina equisetifolia J. R. et G. Forst (fam. Casuarinaceae), Citrus unshiu (Yu. Tanaka ex Swingle) Marcow. (syn. Citrus reticulata Blanco) (fam. Rutaceae), Lantana camara L. (fam. Verbenaceae) and Nerium oleander L. (fam. Apocinaceae),

\subsection{Water Extracts Modeling Leachates}

Water extracts from the intact whole leaves of woody plants were prepared according to ratio $1: 10 \mathrm{w} / \mathrm{v}$ during $1 \mathrm{~h}$, where mainly surface components have leached, as it occurs under strong rain. The extracts filtered from leaf plates through glass filter and used for experiments. This was imitation of leachates from the Donor trees leaf surfaces (with secretory structures) in $1 \mathrm{~h}$-rain, where mainly watersoluble components were leached. This time was enough to wash the water-soluble allelochemicals from leaves surface [5].

\subsection{Ozone Treatment}

Exposures of air-dried leaves from tested plant species to ozone were in the following procedures: 1) under ultraviolet irradiation (ozone 1), 2. acute - short time variant at high gas concentration (ozone 2) or 3. chronic - long-time variant at smaller gas concentration (ozone 3).

In the variant ozone 1, ultraviolet irradiation as the origin of ozone was done by apparatus OUVb-04 "Solnyshko" EAF (Russia). The amount of ozone produced was $0.1 \mu \mathrm{l} / \mathrm{L}$ per 30 $\min$.

In the variant ozone 2, this gas was generated by electric charge Orion-Si ozonator (Russia) during $10 \mathrm{~min}$ in total dose of $0.7 \mu \mathrm{l} / \mathrm{L}$. Chronic exposure in variant ozone 3 occurred with electric charge by ozone generator KPMZ (Russia) in plastic cell volume $439 \mathrm{~cm}^{-3}$. The duration of chronic treatment was $5 \mathrm{~h}$ per day $(5 \mathrm{~h}$ ozone $+12 \mathrm{~h}$ break without the gas) for 3 days (total dose of $0.05 \mu \mathrm{l} / \mathrm{L}$ ).

\subsection{Test for Seed Germination}

The seeds of the test-species, Lavatera trimestris, decorative species, served as a model of plant grown under or near trees and shrubs in the park zone. Lavatera was used as an acceptor of leachates of the woody plant-donors of allelochemicals. Seeds germinated according to the standard method [5] in Petri dishes at $20-22^{\circ} \mathrm{C}$. Ten seeds of acceptor plant Lavatera trimensis were put in each Petri dish $(10 \mathrm{~cm}$ diameter) with filter paper irrigated with $5 \mathrm{ml}$ water extract from leaves of donor woody plants or pure water (control without any additions). In order to know the effect of ozone on leaves, water extract from non-ozonated leaves, in its turn, served as second control in the comparison with the gas effects. The experiments with every variant repeated 4times. Seed germinated were counted $24-36 \mathrm{~h}$ after water extracts application (observation and counting continued for 3 days).

\subsection{Test for Microscopic Images in Transmitted Light of Microscope}

The visual changes in the leaves' samples induced by ozone were observed on subject glasses (slides) under luminescence microscope Leica DM 6000 B in transmitted light, using various objectives 10, 20 and, 40 magnitude.

\subsection{Test of Autofluorescence}

Autofluorescence of leaf surface with secretory structures served as an indicator of the effect at ozone exposure. It was observed at the excitation by light $360-380 \mathrm{~nm}$ and photographed using luminescence microscope Leica DM $6000 \mathrm{~B}$ as described earlier [9-12]. The fluorescence spectra of whole leaves also were recorded with the spectrofluorimeter Perkin-Elmer 350. Registration of such spectra carried out with three repetitions.

\subsection{Test for Fluorescent Determination of the Appearance of Biogenic Amines}

At fluorescent histochemical determination of biogenic amines, glyoxylic acid (reagent for catecholamines, in particular, dopamine) and o-phthalic aldehyde (reagent for histamine) given from Sigma, were used according to the method described for animal cells [13, 14]. Leaves were put on subject glasses (slides) and moistened by drops of $1 \%$ aqueous solutions of glyoxylic acid to determine dopamine [13] or $0.5-1 \%$ solutions of o-phthalic aldehyde to determine histamine [14]. After 10-20 minutes of staining with the reagents, samples were dried at $50-80^{\circ} \mathrm{C}$ during 5-10 min. Fluorescence reaction of forming products in whole leaves was studied under luminescence microscope Leica DM 6000 $\mathrm{B}$ at the excitation by light $360-380 \mathrm{~nm}$. Fluorescence of the samples also measured at 475-485 nm using the spectrofluorimeter Perkin- Elmer 350 (excitation light from 360-380 nm or $430 \mathrm{~nm}$ ). Histochemical reactions repeated (up to three times) for control variants and variants with exposure to ozone. 


\section{Results and Discussion}

We analyzed how water extracts imitated rainfall leachates from woody plant leaves untreated or treated to ozone act to allelopathic activity of herb- acceptor (measured as seed germination). The induced by $\mathrm{O}_{3}$ visual changes in the leaves with well-seen surface secretory structures (which mainly contained allelochemicals leached by rain) were estimated under transmitted light or at excitation by actinic light of luminescence microscope.

\subsection{Seed Germination of Plant-Acceptor}

With or without the ozone treatment, water extracts demonstrated stimulatory or inhibitory activity on the seed germination and in some cases, there was no influence. Extracts of leaves from Eucalyptus cinerea and Brachychiton diversifolius contain stimulatory compounds that increased germination of the test-species, Lavatera by 4-5 times in a comparison with only water in medium (Figure 1). For bottle tree Brachychiton, main known biological activity belongs to caffeine [15], this purine compound also is a stimulator of human nervous system. Genus Eucalyptus has many allelochemicals - flavonoids such as quercetin-3 glycoside and myricetin-3-rhamnoside and volatile aromatic terpenes such as cineol, carvone or $\alpha$ - and $\beta$-pinenes [15]. However, chemical nature of stimulators in rain leachates was not known yet. Ozone significantly decreased stimulatory effects of the leachates either in acute or chronic experiments, for both Eucalyptus and Brachychiton.

Lesser stimulation of the seed germination (up to $50 \%$ of the variant with water only) was in control for Ginkgo (Figure 1). Among biologically active components of the allelopathic species, besides flavonoids (apigenin) and coumaric acid, specific bilobalide and ginkgolide A were reported [15]. Unlike Brachychiton and Eucalyptus, in experiments with Ginkgo biloba, there was no difference between the ozone and control variants.

There was no effect for control for Buddleja davidii and Nerium oleander, but chronic exposure to ozone led to the stimulation of the seed germination by more than $200 \%$ for the first species and by $20-30 \%$ for the second one (Figure 1). Interestingly, that as biologically active compounds for butterfly bush Buddleja genus flavonoids quercetin, kaempferol and linarin are known, while for $N$. oleander steroids (cardenolides) gitoxygenin, karabin, cornerin and neriodorin were reported [15]. Perhaps, chronic exposure in ozone made transformations in these compounds. Water extracts from leaves of Casuarina and Lantana had no marked allelopathic activity at all, neither without nor with ozone (Figure 1). In variant with Citrus unshiu, under ozone the $100 \%$ inhibition was seen (non-illustrated) in a comparison with weak allelopathic activity in the control.

\section{Eucalyptus Ginkgo Lantana Nerium}

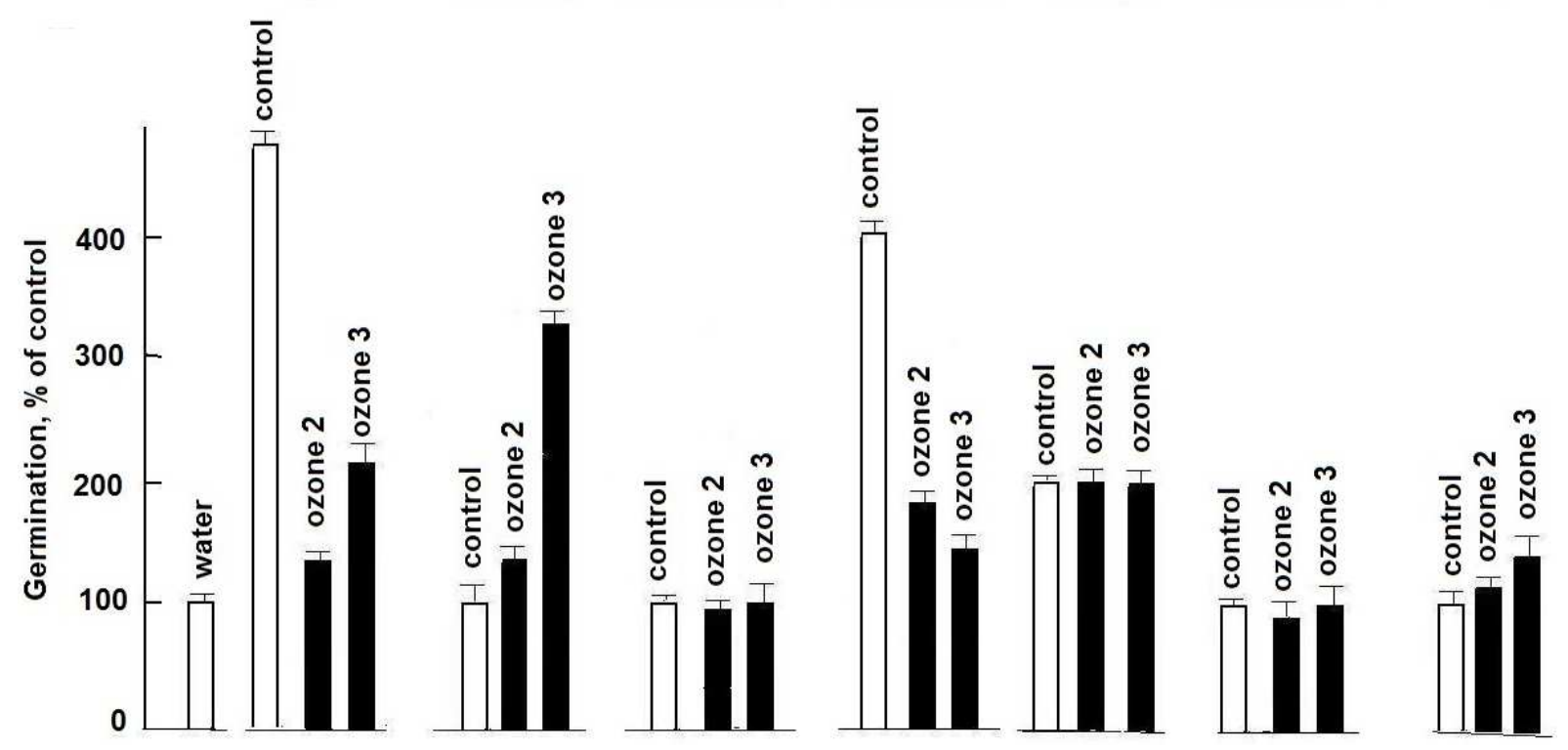

Figure 1. Allelopathic activity of water extracts from leaves of woody plants undergone to ozone estimated on seed germination of Lavatera trimestris, under pure water. Control (with water extracts from untreated leaves), water extracts from leaves treated with ozone 2 (acute ozonation), or ozone 3 (chronic ozonation). Results were expressed as mean \pm the standard error of the mean $(n=40-50$ seeds per variant).

Among biologicaly active compounds possible to regulate the seed germination are flavonoids quercetin, kaempferol and linarin for Brachychiton spp. and for Buddleja officinalis; the monoterpene and sesquiterpene derivatives in essential oil for Eucalyptus cinerea, anacardic acid, bilobalide, riboflavin, triterpenoids- ginsengosides for Ginkgo biloba; adinerin, cardenolides, karabin for Nerium oleander [15-17]. Essential oils of Eucalyptus genus, expressed a peculiar inhibitory action on the growth processes $[17,18]$.

Leachates from allelopathically active trees and shrubs are known for some species, for example for genus Eucalyptus. The leaching induced inhibition of agricultural plants like Phaseolus aureus and Lens esculentum. Most evident 
allelopathic potential belonged to volatiles such as cineol and phenolic compounds such as syringic acid [17-20]. According to other findings, excretions from various species of the Eucalyptus genus may act on agricultural plants both as inhibitors and stimulators depending on the taxonomic position $[18,19,21]$. It is especially significant for Australian and Indian Species valuable for economic policy of these tropic countries [22]. The depressive influence of Eucalyptus leaf extracts on grass seeds was also reported [23].

\subsection{Leaf Secretory Structures Seen Under Microscope}

Plant-donors of allelochemicals may contain these compounds in secretory structures $[7,10,11,16]$. In

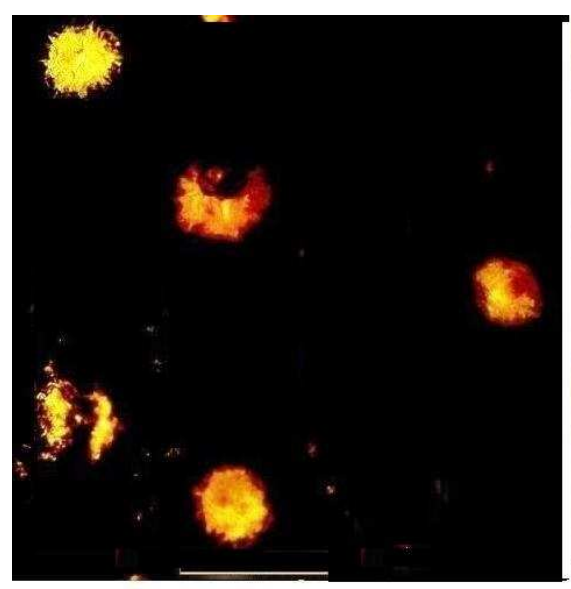

Without treatment transmitted light of usual microscope, the action of ozone is possible to see in leaf oil glands of Eucalyptus cinerea before and after exposure. Treatment by $\mathrm{O}_{3}$ induced fast changes in colour of the structure (Figure 2). Orange, yellow and even red coloured glands in one moment became yellowish-green and dark green. The middle part of some visible glands seems pale yellow after the exposure (Figure 2). Phenolic pigments (flavones, anthocyanins) that contributed in the colour of the secretory cells fulfilled oil appears to bleach under oxidation. Out of secretory structures, the chlorophyll amount appears to decrease because in the control it looks dark green in a comparison with secretory structures treated with ozone (Figure 2).

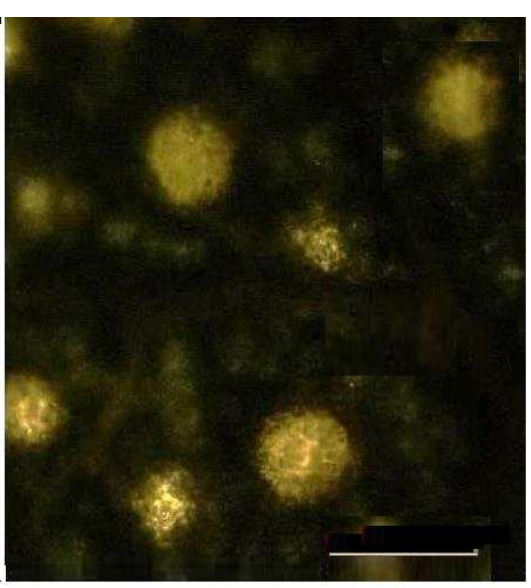

After exposure in ozone

Figure 2. The colour changes in the secretory structures of the leaf of Eucalyptus cinerea after acute exposure to ozone (0.5-0.7 $\mu l / L)$ during 10 min, observed under transmitted light of microscope. Bar $=200 \mu \mathrm{m}$.

According to some authors [24], oxygen, ozone and Ultraviolet that form ozone, induced bleaching of the tissues of Eucalyptus. The decrease in chlorophyll a fluorescence of Citrus also has reported by Calatayud with co-workers [25].

\subsection{Autofluorescence of Leaves}

Most intact secretory cells showed multicomponent fluorescence spectra, and it is necessary to know the chemical composition of the prevailing components by comparing with the emission of individual known components $[10-12,26]$. The leaf autofluorescence has changed after ozone exposure (Figure 3 ).

If autofluorescence in control, without ozone, was weak

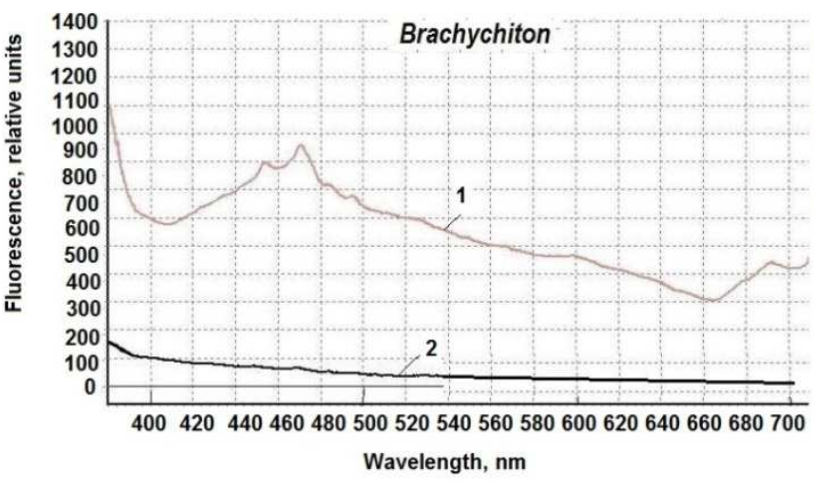

(in Lantana and Citrus), after the exposure in $\mathrm{O}_{3}$ common emission increased significantly, and clear maxima arose in blue (450 and $470 \mathrm{~nm})$ spectral region and sometimes in red (675 or $685 \mathrm{~nm})$. On the contrary, autofluorescence of Brachychiton, in the control marked maxima 450 and $470 \mathrm{~nm}$ in blue; after ozonation it demonstrated the lack of any peaks in the emission spectrum and drop in common fluorescence intensity. Although leaves of Nerium showed small maxima in the control emission spectrum, clear peaks, and the increase in common fluorescence intensity were observed at chronic exposure to ozone. In the fluorescence spectra of Citrus, after both acute and chronic exposure to ozone, there were maxima in blue.

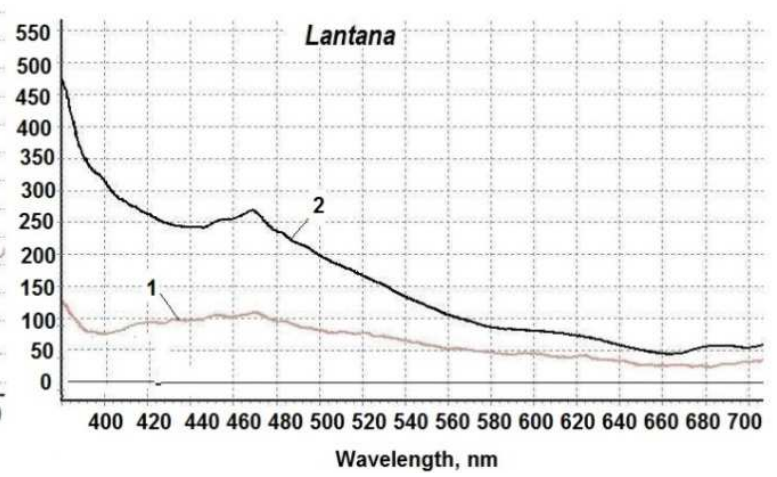



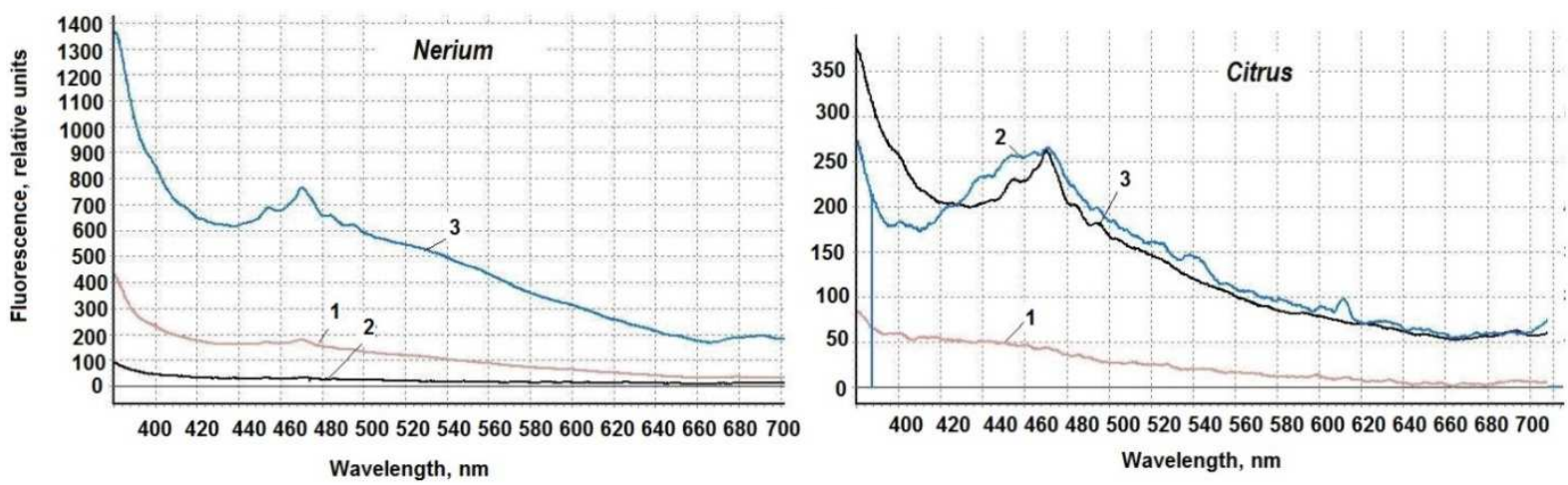

Figure 3. The fluorescence spectra of leaves from Brachychiton davidii, Lantana camara, Nerium oleander and Citrus unshiu. (1) - control, without

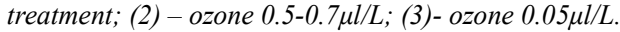

Usually, the compounds that lye on the surface and in secretory cells may be extracted by hydrophilic or /and hydrophobic compounds that changes the fluorescence characteristics of the surface [26]. One of example is on Figure 4 for leaf image of Eucalyptus before or after extraction with water or ethanol. When the sample was not treated, the leaf surface of Eucalyptus cinerea looks brightly in pale green; only cells of sheath around dark glands fluoresce are in darker green (Figure 4, a). Water extraction of possible phenolic compounds made the surface more green emitted (Figure 4, b). Only after extraction with ethanol, red fluorescence, peculiar to chlorophyll, lying deeply in parenchyma was observed (Figure 4, c), It was due to the ethanol extraction of terpenoid fluoresced in blue, and the red emission of chlorophyll was seen clearly (Figure 4, c).

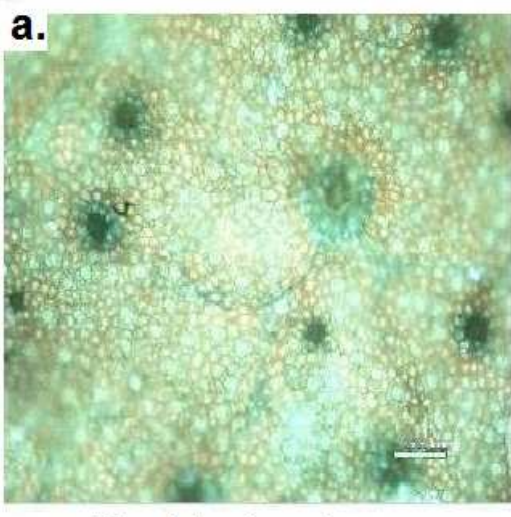

without treatment

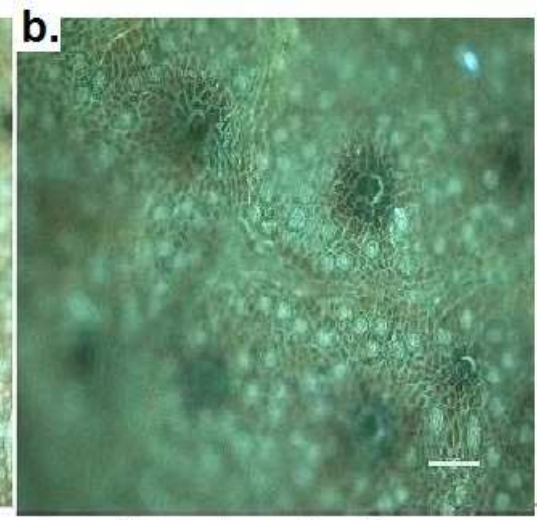

after water extraction

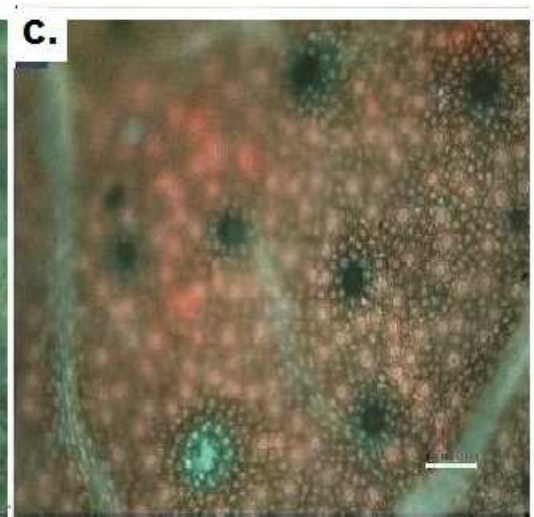

after ethanol extraction

Figure 4. Fluorescent images of the leaf surface of Eucalyptus cinerea after extraction by water (b) or ethanol (c), compared to control (a). Excitation 430 nm. Bar $=100 \mu \mathrm{m}$.

Autofluorescence of plant leaves' surface studied linked with the terpenoids and flavonoids maxima seen at $400-440$ $\mathrm{nm}$ and $470-480 \mathrm{~nm}$ for an excitation at $360 \mathrm{~nm}$ (Figure 3, Table 1). Some weak maxima $670-685 \mathrm{~nm}$, peculiar to chlorophyll, were also observed; but were well seen at the excitation of $430 \mathrm{~nm}$ after extraction from intact whole leaf by water or ethanol in ratio $1: 10 \mathrm{w} / \mathrm{v}$ per $1 \mathrm{~h}$, when some flavonoids or terpenes from the surface released, relatively. Blue colour autofluorescence (420-430 nm) of the leaf surface was, perhaps, as related to the presence of blue pigments azulenes found in Eucalyptus cinerea [27]. Summed data in Table 1 showed different autofluorescence characteristics of the leaf surface. Among species studied, leaf autofluorescence of Brachychiton diversifolius and Buddleja davidii were absent at chronic and acute exposures to ozone formed by electric charge, except ultraviolet irradiation, where maxima 456 and $470 \mathrm{~nm}$ were seen (Table 1). For Nerium, similar effect was seen only at acute exposure, while in chronic variant of experiment additional new maxima 450 and $680 \mathrm{~nm}$ (in control was only one $470 \mathrm{~nm}$ in blue region) were observed. In Citrus unshiu, which has no fluorescence in control, under $\mathrm{O}_{3^{-}}$ exposure the emission arose (maxima 454, 479, $690 \mathrm{~nm}$ at chronic exposure or 470 and $610 \mathrm{~nm}$ at acute exposure) and strongly increased. Eucalyptus, cinerea was especially sensitive to ozone: new peaks 425 and $430 \mathrm{~nm}$ appeared in the chronic and acute exposures with ozone. In variants with Eucalyptus, maximum $470 \mathrm{~nm}$, peculiar to phenols, was both in control and after all treatments. However, under ozone related to terpenoids peaks in region 400 and $413 \mathrm{~nm}$ disappeared (Table 1). 
Table 1. Influence of ozone or ultra-violet irradiation on the fluorescence maxima of the dried leaves with allelochemicals. Excitation $360 \mathrm{~nm}$.

\begin{tabular}{lllll}
\hline Plant species & Fluorescence maxima, $\mathbf{n m}$ & & & \\
\cline { 2 - 5 } & $\begin{array}{l}\text { Control (without } \\
\text { treatment) }\end{array}$ & $\begin{array}{l}\text { Ozone (dose } \mathbf{0 . 0 5} \boldsymbol{\mu l} / \mathbf{L} \\
\text { during 3 days) }\end{array}$ & $\begin{array}{l}\text { Ozone (dose 0.5-0.7 } \\
\boldsymbol{\mu l} / \mathbf{L} \text { during 10 min) }\end{array}$ & $\begin{array}{l}\text { UV-irradiation }\left(\mathbf{O}_{3}>\mathbf{0 . 1} \boldsymbol{\mu l} / \mathbf{L}\right) \\
\mathbf{3 0} \text { min. Analysis after 24 h }\end{array}$ \\
\hline $\begin{array}{l}\text { Brachychiton diversifolius } \\
\text { Buddleja davidii }\end{array}$ & $452,470,600,685$ & 0 & 0 & 456,470 \\
Citrus unshiu & 470,680 & 0 & 0 & 450 \\
& No emission & $454,479,690$ (high & 470,610 & 460 \\
Eucalyiptus cinerea & $400,413,450,470,680$ & $425,450,470,675$ & $430,450,470,485,490$, & 454,470 \\
Nerium oleander & 470 & 450,680 & small 680 peak & 470 \\
\hline
\end{tabular}

For Nerium, action of ozone led to arise new maxima 450 and $680 \mathrm{~nm}$ at chronic exposure and the absence of any peaks after acute treatment. Generally, the maximum 680-685 nm, peculiar to chlorophyll, decreased or disappeared in studied plants under ozone exposure like for Citrus leaves [25] and flower petals of Saintpaulia ionantha [28].

Treatment with ultra-violet irradiation, which also produced ozone, also resulted in marked changes in autofluorescence (Table 1). Like chronic and acute experiments with ozone formed by electric charge, here are maxima in blue at $400-413 \mathrm{~nm}$, peculiar to terpenoids, also disappeared in leaves of Eucalyptus. After the UV- treatment, maximum $470 \mathrm{~nm}$, seen in control and related to phenols, registered for three species (Brachychiton, Eucalyptus and Nerium) out of five. New maxima at region 450-456 nm arose (Brachychiton and Buddleja) or were the same as in the control (Eucalyptus). In Citrus, only peak $460 \mathrm{~nm}$ was after UV-irradiation. Autofluorescence of plant leaves' surface studied linked with the terpenoids and flavonoids maxima seen at 400-440 $\mathrm{nm}$ and $470-480 \mathrm{~nm}$ for an excitation at 360 nm (Figure 3, Table 1). Equal maxima seen under both ozone and UV-irradiation are at 450-456 $\mathrm{nm}$ (Brachychiton, Buddleja and Eucalyptus) or/and at $470 \mathrm{~nm}$ (Brachychiton, Nerium and Eucalyptus). At all ozone exposures, we can see changes may be related to Only long-term exposure of Citrus unshiu reported to induce a decrease in photosynthesis and chlorophyll fluorescence [25] transformations of allelochemicals or even new compounds may arise.

The contribution of individual allelochemicals in the fluorescence that may be observed after the dried sample exposure to ozone and then dissolution in water or in ethanol (2 $\mathrm{mg} / \mathrm{ml}$ ) was confirmed by earlier works [3, 26, 28]. Some known allelopathic compounds - phenols, terpenoids and alkaloids - are given in Table 2. Among chosen compounds, flavonoid anthocyanin pelargonidin that has been dissolved in water or in ethanol after the exposure in ozone was most sensitive to ozone because characteristic maximum $665 \mathrm{~nm}$ disappeared first after $25 \mathrm{~h}$ exposure in ozone at small dose 0.05 $\mu \mathrm{l} / \mathrm{L}$ [28]. For terpenoids absinthin and azulene solved in ethanol, the changes occurred at higher dose of $\mathrm{O}_{3}$, the maximum 540 $\mathrm{nm}$ of the first compound shifted in blue spectral region, while maximum $400 \mathrm{~nm}$ of second substance disappeared (Table 2).

It is similar with our data of Table 1, where in the leaf spectra maxima at range $400-430 \mathrm{~nm}$ were absent after the ozone treatment, for example in variant Eucalyptus that contains azulenes [27]. Chlorophyll was not too sensitive to ozone in a comparison with flavonoid anthocyanin, with a decrease to a maximum of $675-680 \mathrm{~nm}$ after only to $100 \mathrm{~h}$ in chronic exposure (dose $0.2 \mu / \mathrm{L}$ ) to ozone action (Table 2). Only long-term exposure of Citrus unshiu reported to induce a decrease in photosynthesis and chlorophyll fluorescence [25].

Tolerant compound to all used doses of ozone was alkaloid berberine. Like berberine, chlorogenic, ferulic and caffeic

Table 2. The effects of ozone on the fluorescence maxima of individual compounds solved in $96 \%$ ethanol (2 $\mathrm{mg} / \mathrm{ml}$ ). Excitation $360 \mathrm{~nm}$.

\begin{tabular}{|c|c|c|c|c|}
\hline \multirow{3}{*}{ Individual compound } & \multicolumn{4}{|c|}{ Maximum, nm/ Fluorescence intensity changes } \\
\hline & \multirow{2}{*}{ Control } & \multicolumn{3}{|c|}{+ dose of ozone $(\mu \mathrm{l} / \mathrm{l})$} \\
\hline & & $0.05(25$ h) & $0.1(50$ h) & $0.2(100 \mathrm{~h})$ \\
\hline Anthocyanin pelargonidin (pH 5.5.) & $450-460,665$ & $450-460$ & $410-420 /$ decrease & 0 \\
\hline Absinthin & 540 & 540 & $470,450 \mathrm{~nm}$ & 470 \\
\hline Azulene & $380-430$ & 400 & 400 (no maxima) & 400 (no maxima) \\
\hline Berberine & 540 & 540 & 540 & 540 \\
\hline Chlorophyll & $675-680$ & $675-680 *$ & 675-680/increase & $675-680 /$ decrease \\
\hline Ferulic acid & $450-460$ & $450-460 *$ & $450-460 *$ & $450-460 *$ \\
\hline Cinnamic acid & $450-460$ & $450-460 *$ & $450-460 *$ & $450-460 *$ \\
\hline Esculetin (Aesculetin) & $500-520$ & $450 *$ & $450 /$ decrease & $450 /$ decrease \\
\hline Coumaric acid & 450 & $450 *$ & $450 *$ & $450 *$ \\
\hline
\end{tabular}

*No changes in the emission intensity. Sources: 26, 28 and unpublished data for azulene and berberine.

acids as well as coumaric acid that after ozonation in all doses, solved in water or ethanol fluoresced in blue with maxima at 450-460 $\mathrm{nm}$ [29]. They changed neither maxima position, no the emission intensity during acute or chronic exposures [28]. Unlike coumaric acid, the emission of esculetin, a coumarin derivative, at $450 \mathrm{~nm}$ under chronic $\mathrm{O}_{3}$ (0.1- $0.2 \mu / \mathrm{L}$ doses) decreased, and maximum in the spectra from $500-520 \mathrm{~nm}$ shifted to short-wavelength to $450 \mathrm{~nm}$ 
(Table 2). It should know, that 7-alkoxy coumarins generally have a purple fluorescence, whereas 7-hydroxy and 5,7dihydroxycoumarins tend to fluoresce in blue [29]. Ozone is capable to change the phenol composition in Citrus plant [30] that seen from fluorescence of whole leaves (Table 1).

\subsection{Analysis of the Appearance of Dopamine and Histamine as Agents of Stress}

It has established that not only animals, but also plant and microbial cells form dopamine and histamine under a variety of stresses [31-34]. Dopamine and histamine, known as neurotransmitters of mammalians and found in plants and microorganisms, can accumulate in cells. They also showed allelopathic features [32]. The criterion for histochemical reactions of these biogenic amines is the appearance of blue fluorescence at range 460-480 nm excited by ultraviolet light $360 \mathrm{~nm}$. After the histochemical staining with glyoxylic acid, the emission maximum was at 470-480 nm, while with o-phthalic aldehyde the emission peak was at $460 \mathrm{~nm}$. After chronic or ozone exposure, histochemical reactions for biogenic amines on the leaf surfaces of woody species were established (Table 3 ). In all control variants, there were no detectable fluorescent reactions for dopamine, but after the treatment with ozone, one can see the blue emission of the cells around dark glands in samples from Eucalyptus and Citrus. After similar exposure, one found blue emission related to dopamine exactly in secretory cells (laticifers) of Nerium. Unlike results with dopamine the reaction for histamine (also lack in control) appeared after the acute ozone exposure and was marked in glands and stomata in Buddleja and in some parts of glands in Eucalyptus. However, histamine was absent in Nerium both in control and after ozonation. It is known [14] that at high stress concentration of histamine $\left(10^{-3} \mathrm{M}\right.$ or higher) in tissues, one can see yellow emission. In the experiments, we observed similar yellow fluorescence in cells around dark glands of Citrus that should mark high concentration of histamine in the sample. Both biogenic amines dopamine and histamine were found in Citrus and Eucalyptus, while in other species either first or second compound recorded (Table 3 ).

Table 3. The fluorescence of secretory structures after histochemical staining with glyoxylic acid and o-phthalic aldehyde for determination of dopamine and histamine, relatively, formed after chronic or acute ozone exposures. Excitation $360 \mathrm{~nm}$.

\begin{tabular}{lll}
\hline \multirow{2}{*}{ Species } & Staining with & o-phthalic aldehyde \\
\cline { 2 - 3 } & glyoxylic acid & Increased blue fluorescence in glands and stomata (histamine) \\
\hline Buddleja davidii & No blue emission & Yellow fluorescence in cells around dark glands (histamine in \\
Citrus unshiu & $\begin{array}{l}\text { Increased blue fluorescence in cells around dark glands } \\
\text { (dopamine) }\end{array}$ & high concentrations) \\
Eucalyptus cinerea & Increased blue fluorescence around dark glands (dopamine) & Blue fluorescent parts of glands (histamine) \\
Nerium oleander L. & Blue fluorescence of secretory cells (dopamine) & No blue emission \\
\hline
\end{tabular}

These are qualitative data, which demonstrated the presence of the allelochemicals- biogenic amines-on the surface of leaves of woody plants after the exposure to ozone. Receiving of quantitative fluorescent data from secretory cells may be a separate task with the use of special apparatuses in Future.

By applied histochemical methods, we saw a location of the compounds in some secretory structures and out them. The presence of biogenic amines on the leaf surface with secretory structures shows the possibility to release the compounds via the rain leachates.

Dopamine and histamine are known to regulate the fertilization and stimulate the pollen germination of Hippeastrum hybridum as well as the seed germination of Raphanus sativus [32-34]. Under ozone treatment in Nature, the amount of dopamine and /or histamine increases in pollen of many allelopathically active species, such Coryllus avellana and Populus balsamifera $[31,32]$

\section{Conclusion}

Model experiments with allelopathically active woody species have shown that the duration and intensity of ozone exposure influenced the ability of their allelochemicals from rain leaf leachates to act on herbs grown under or near the trees. The test-reactions on tropospheric ozone stress may use in the analysis of the allelopathic relations in urban conditions. They include spectral characteristics of leaves (the color and autofluorescence of secretory cells, containing allelochemicals with surface secretory structures) changed under ozone treatment. As indicator of the changes also serves the formation of biogenic amines - dopamine and histamine in cells under ozone stress. Future studies as in model and natural conditions may be important for the formation of plantings in urban conditions, basing on characteristics of studied species, to recommend the valuable woody species for parks. Ornamental trees like Brachychiton, Buddleja, and Eucalyptus are widely cultivated in many countries of subtropics and tropics. They are exploited as medicinal and economical cultures. Their rain leachates revealed the presence of growth stimulators that is valuable for the germination of herbal species grown in the tree vicinity.

\section{Acknowledgements}

Author thanks Dr. Soltani G. A. for the collection of woody plant samples in Sochi National Park (Dendrarium) and is grateful for use the equipment of Optical Microscopy and Spectrophotometry core facility, ICB RAS, Federal Research Center "Pushchino Scientific Center for Biological Research of the Russian Academy of Sciences" in some experiments. 


\section{References}

[1] D. V. Bates. "Ambient Ozone and Mortality." Epidemiology, vol. 16, N 4. pp. 427-429, 2005.

[2] S. N. Kotelnikov, E. V. Stepanov, and V. T. Ivashkin. "Ground ozone concentrations and health of different age population groups in Moscow in summer 2010." Geophysical Processes and Biosphere, vol. 18 (4). pp. 26-38. https://doi.org/10.21455/GPB2019.4-3, 2019.

[3] V. V. Roshchina and V. D. Roshchina. "Ozone and Plant Cell." Dordrecht: Kluwer Academic Publishers, 2003.

[4] J. G. Calvert, J. J. Orlando, R. William, W. R. Stockwell., and T J. Wallington. "The Mechanisms of Reactions Influencing Atmospheric Ozone”. Oxford: Oxford University Press. 2015.

[5] E. Rice. “Allelopathy.” Orlando: Academic Press. 1984.

[6] S. S. Narwal. "Allelopathy in crop production." Jodhpur: Scientific Publishers, 1994.

[7] V. V. Roshchina. "Molecular-cellular mechanisms in pollen allelopathy. "Allelopathy J. vol. 8 (1), pp. 11-28. 2001.

[8] G. A. Soltani, I. V. Annenkova., G. L. Orlova and A. V. Yegoshin. "Plant collection of Sochi «Arboretum»". Annotated Catalogue. Sochi: Sochi National Park. 2016.

[9] V. V. Roshchina. "Autofluorescence of plant secreting cells as a biosensor and bioindicator reaction." J Fluoresc, vol. 13 (5), pp. 403-20. 2003.

[10] V. V. Roshchina. "Cellular models to study the allelopathicmechanisms." Allelopathy J, vol 13 (1), pp. 3-16, 2004.

[11] V. V. Roshchina. "Allelochemicals as fluorescent markers, dyes and probes.” Allelopathy J, vol. 16 (1), pp. 31-46. 2005.

[12] V. V. Roshchina. "Vital autofluorescence: Application to the study of plant living cells." Int J Spectroscopy, vol. ID 124672, pp. 1-14, doi: 10.1155/2012/124672, 2012.

[13] L. N. Markova, G. A. Buznikov, N. Kovačević., L. Rakić, N. B. Salimova, and E. V. Volina. "Histochemical study of biogenic monoamines in early ("Prenervous") and late embryos of sea urchins". International Journal of Developmental Neuroscience, vol. 3 (5), pp. 493-495, 497499.1985 .

[14] S. A. M. Cross, S. W. B. Even, and F. W. D. Rost. " A study of the methods available for the cytochemical localization of histamine by fluorescence induced with o-phthalaldehyde or acetaldehyde". Histochemical Journal, vol. 3 (6), pp. 471-476. 1971.

[15] B. N. Golovkin, R. N. Rudenskaya, I. A. Trofimova, A. I, Shreter. "Biologically active substances of plant origin." Moscow: Nauka, 3 volumes. 2001.

[16] A. Grichi, Z. Nasr, and M. L. Khouja.” Phytotoxic effects of essential oil from Eucalyptus cinerea and its physiological mechanisms."J of New Sciences, vol. Spéciale - Conférence IABC 2015, Article 13, pp. 1-14. 2015.

[17] R. K Kohli. "Allelopathic implications of Eucalyptus in agroecosystems." in Allelopathy in agriculture and forestry, S. S. Narwal and P. Tauro. Eds. Jodhpur: Scientific Publishers, pp.
75-91. 1994.

[18] S. S. Narwal. "Allelopathic effects of eucalyptus in agroforestry." in Trees and tree farming. P. K. Thampan Ed. Cochin: Peekay Tree Crops Development Foundation. pp. 295-316.1994.

[19] S. S. Narwal. "Allelopathy related problems in crop production, agroforestry and horticulture." in: Allelopathy: Field observations and methodology, S. S. Narwal and P. Tauro, Eds. Jodhpur: Scientific Publishers, pp. 1-40. 1996.

[20] P. L. C. A., Alves, R. E. B Toledo, and A. V. Gusman. "Allelopathical potential of Eucalyptus spp." in: Allelopathy Update, vol. 2. Basic and Applied Aspects. S. S. Narwal, Ed. Enfield: Science Publisher, pp. 131-148.1999.

[21] D. P. S. Nandal, S. S. Bisla, S. S. Narwal and J. C. Kaushik. "Allelopathicinteractions in agroforestry systems. "in Allelopathy in agriculture and forestry, Narwal S. S., and Tauro P, Eds. Jodhpur: Scientific Publishers, pp. 93-130.1994.

[22] R. Willis. "Allelopathy in Eucalyptus: Australian studies." in: Allelopathy: Field observations and methodology, S. S. Narwal and P. Tauro, Eds, Jodhpur: Scientific Publishers, pp. 41-64. 1996.

[23] F. P. Carvalho, C. A. D. Melo, M. S. Machado, D. C. F. S. Dias. "The Allelopathic Effect of Eucalyptus Leaf Extract on Grass Forage Seed. Planta daninha. vol. 33, no. 2, Viçosa Apr. /June 2015, http://dx.doi.org/10.1590/0100$83582015000200004,2015$.

[24] S. A. Lemos de Morais, K. C. Carrijo, A. M. L. Castro, D. A. Ferreira, E. A. Nascimento. "Oxygen and ozone bleaching of Eucalyptus kraft pulp with and without UV radiation". Ciencia y Engenharia/ Science and Engineering Journal, vol. 10, Issue 2, July 2001, pp. 141-144. 2001.

[25] A. Calatayud, D. J. Iglesias, M. Talón, E. Barreno. "Effects of long-term ozone exposure on citrus: Chlorophyll a fluorescence and gas exchange." Photosynthetica, vol. 44, pp. 548-554. 2006.

[26] V. V. Roshchina. "Fluorescing World of Plant secreting Cells". Enfield, Plymouth: Science Publisher. 2008.

[27] D. A. Konovalov. "Natural azulenes". Plant Resources (Russia), vol. 31 (1), pp. 101-130. 1995.

[28] V. V. Roshchina, N. E. Shvirst, and A. V. Kuchin.” The Autofluorescence Response of Flower Cells from Saintpaulia ionantha as the Biosensor Reaction to Ozone." Computational Biology and Bioinformatics, vol. 4 (6), pp. 60-66. Published online: Mar. 23, 2017 doi: 10.11648/j.cbb.20160406.13, 2017.

[29] O. S. Wolfbeis. "The fluorescence organic natural product". in Molecular Luminescence Spectroscopy. Methods and Applications. S. G. Shulman, Ed., pp. 167-370. New York, Chichester Brisbane: Wiley. 1985.

[30] X. Zhu, J. Jiang, C. Yin,, G. Li, Y. Jiang, Y. Shan. "Effect of Ozone Treatment on Flavonoid Accumulation of Satsuma Mandarin (Citrus unshiu Marc.) during Ambient Storage. "Biomolecules vol. 9 (12), pp. 821-835. 2019. https://doi.org/10.3390/biom9120821- 2019.

[31] V. V. Roshchina. "Model Systems in the Study of the Secretory Function of Higher Plants". Berlin, Heidelberg: Springer. 2014. 
[32] V. V. Roshchina and V. A. Yashin. "Neurotransmitters catecholamines and histamine in allelopathy: Plant cells as models in fluorescence microscopy." Allelopathy Journal, vol. 34 (1), pp. 1-16. 2014.

[33] V. V. Roshchina and E. V. Melnikova. "Allelopathy and plant generative cells. Participation of acetylcholine and histamine in a signalling at the interactions of pollen and pistil". Allelopathy Journal. vol. 5 (2), pp. 171-182. 1998.

[34] V. V. Roshchina. "Neurotransmitters in Plant Life". Enfield, Plymouth: Science Publisher. 2001. 